\title{
Early adopters of carsharing with and without BEVs with respect to gender preferences
}

\author{
Ines Kawgan-Kagan ${ }^{1}$ (D) \\ Received: 2 January 2015 / Accepted: 22 September 2015 /Published online: 1 October 2015 \\ (C) The Author(s) 2015. This article is published with open access at SpringerLink.com
}

\begin{abstract}
Purpose The majority of current e-carsharing users are middle-aged men with a high education and high income; they are most likely to have a full-time employment. Women are consistently underrepresented in previous studies and therefore this paper focusses on characterization of female early adopters. It builds a basis to identify current female early adopters and understand their preferences in e-carsharing in order to address women as target groups for e-carsharing. Methods A sample of 492 carsharing subscribers from Berlin is analysed according to socio-demographic backgrounds, mode choice, use and evaluation of (e-) carsharing services. Additionally, attitudinal indices and clusters based on mobility related attitudes are analysed to reveal significant differences between male and female users.

Results Generally, the results confirm socio-demographic findings from previous literature about early adopters. Comparing females and males revealed differences in income, employment status and age. Female early adopters used battery electric vehicles (BEVs) more often than vehicles with an internal combustion engine and evaluate handling BEVs more positive. They show a higher bike affinity and lower affinities
\end{abstract}

This article is part of the Topical Collection on Driving Societal Changes towards an Electro-mobility Future

\section{Description:}

This Paper is part of a multimethodological study to answer the question on how women can be addressed as target groups for e-carsharing. It builds a basis to identify current female early adopters and understand their preferences in e-carsharing.

Ines Kawgan-Kagan

ines.kawgan-kagan@tu-berlin.de

1 Institute of Land and Sea Transport, Technical University Berlin, Berlin, Germany towards technology and innovation than male respondents. They combine public transportation and bicycling with the use of (e-) carsharing services as an additional part of urban mobility. Children do not seem to have an impact of the respective topics, although the findings suggest that services are not used with children.

Conclusions The analysis of carsharing schemes needs to focus on specific requirements of each trip (e.g. transporting or accompanying children) in order to make sustainable mobility an option for others than one 'typical early adopter'.

Keywords Female early adopters $\cdot$ Carsharing $\cdot$ BEV . Gender differences $\cdot$ E-mobility $\cdot$ Women $\cdot$ Mobility related attitudes $\cdot$ Sustainable urban mobility

\section{Introduction}

Carsharing with battery electric vehicles (BEVs) can help reducing urban space scarcity, local and global emissions and noise exposure. However, operating a carsharing scheme with electric vehicles is more expensive and offers users less autonomy than carsharing powered by internal combustion engines (ICEVs). Thus, carsharing operators need to identify and address target groups for these mobility services. The majority of electrical vehicles owners are urban or suburban middle-aged men with high education and high income; they usually live in a household that owns more than one car and are most likely to have a full-time employment $[1,2]$. Sociodemographic characteristics of early adopters of carsharing are congruent with the identified characterisations of early adopters of electrical vehicles. Carsharing subscribers are mainly between the age of 35 and 45 years, with a higher education and income [3-5]. International studies showed a higher environmental awareness of both groups of early 
adopters. It becomes salient that women are consistently underrepresented in previous studies and therefore special analyses should give insights beyond the typical 'early adopter'.

In general, adult women are more likely to head for multiple destinations and their mobility includes more complex trip chains due to their traditional social role, which involves responsibility for shopping and family errands [6-8]. These trips usually are of shorter distances and, therefore, could be easily covered by using e-carsharing services in urban areas. Women show greater awareness of environmental issues [9] and have a more positive attitude towards ecological measures like reducing car use and using public transportation (PT) [10]. While taking greater household and family responsibilities, women can be role models for the future generation and creating a shift towards sustainable mobility services since parents have an impact on the travel behaviour of their children [11]. However, exact requirements and preferences of women have to be identified.

For the first time a sample collected within the BeMobility 2.0 project by the Innovation Center for Mobility and Societal Change (InnoZ) containing carsharing and e-carsharing subscribers from Berlin is analysed to get insights about female early adopters presented in this paper. After presenting relevant literature including findings about early adopters in general and differences between women and men, a sample of early adopters of carsharing with and without BEVs of Berlin is analysed and set into a relation to the Berlin and were possible the German population.

The findings are the first step in a multimethodological study to answer the question on how women can be addressed as target groups for e-carsharing. It builds a basis to identify current female early adopters and understand their preferences in carsharing with and without BEVs.

\section{Characterisation of early adopters of carsharing and BEVs}

Analysing the characteristics of female early adopters of carsharing with and without BEVs, as a first step, early adopters in general have to be considered according to previous literature. Therefore, this section focusses on an overview of the characterisations of early adopters of BEVs and of carsharing according to previous studies. Important aspects for the characterisation of female early adopters are drawn.

In order to characterise early adopters of carsharing with and without BEVs, following previous findings of analyses of carsharing subscribers and BEV owners is presented. Previous international literature shows a high consistency of sociodemographic characteristics for early adopters of BEVs. The majority of BEV owners are middle-aged men with a high education and high income [12]; they usually live in a household that owns more than one car [13] and are most likely to have a full-time employment [1]. Additionally, BEV owners and users are wealthy and keep multiple cars, whereas they use the BEV as an addition to their private car. Most of the BEV owners live in households with more children than the average $[2,14]$. In terms of socio-demographics, international surveys showed that potential owners of BEVs bear resemblance to actual owner characterisation: The majority are middle-aged males with a high income and education, a high eco-sensitivity and living in larger cities $[15,16]$. An analysis of driving profiles from the large scale study 'Mobilitaet in Deutschland 2008' [17] in Germany shows, that for respondents from larger cities owning an BEV would not be an economic option due to the high initial costs [1]. The authors conclude that people living in cities with less than 20,000 inhabitants could have the highest economic benefits of BEV ownership: Usually, urban profiles include too low driving frequencies and too short distances for the lower price of propulsion to balance the total costs of ownership. Nevertheless, most of the BEV owners live in or near larger cities [18, 19]. This leads to the assumption that economic considerations cannot be the only factor for purchasing a BEV. Thus, other factors have to affect the purchase decision. The BEV market segment shows a higher environmentally awareness and technological affinity [20,27]. Most of the studies reveal lifestyle [13] as well as technological and economic reasons as important motivating factors owning a BEV [21]. Other studies contradict, naming interest in cutting-edge technologies as the crucial factor and not environmental issues [19].

The socio-demographic background for early adopters of carsharing is congruent with the identified characterisations of early adopters of BEVs. Carsharing subscribers are mainly male and between the age of 35 and 45 years, with a higher education and income $[4,5,22]$. Referring to merely free floating carsharing services, which presents a new mobility service, more than half of the users are male and younger than 35 with a high share of full-time employment [5, 23]. Additionally, in general carsharing subscribers have a higher income [5, 23], although Petersen found a lower income in his sample from the early nineties [24]. Carsharing subscribers mainly live in larger cities [3]. Most of the studies attest carsharing subscribers a high affinity towards environmental issues and a high affinity towards public transportation [24-26].

Less consistent is the characterisation regarding attitudes even for the respective early adopters: several studies identified lifestyle [13], technological affinity and economical awareness as crucial factors influencing buying decisions and the usage of carsharing services [20,21, 27]. Nevertheless, there are contradicting results naming higher affinity towards new technologies and not environmental awareness for owners of BEVs [19]. Carsharing users show a higher affinity towards public transportation [24-26]. In contrast, BEV owners usually have more than one car in the household 
[13]. The findings about differing attitudes indicate that there is not only one type of early adopter of carsharing with BEVs regarding attitudes. In 2015 Hinkeldein et al. [28] present an attitude-based typology to cluster a representative sample into six groups with different attitudinal profiles. There are mainly two clusters with a high potential for using e-carsharing schemes: 'innovative technology-loving multioptionals' and 'ecological PT- and bike-lovers'. Both clusters show a high level of mobility related environment awareness, high affinities regarding mobility services, public transportation (PT) and long-distance train and regarding innovations. Differences can be found concerning the joy of car driving, the general car affinity and the affinity towards new technologies.

According to previous identified aspects, for a characterisation of female early adopters the following aspects need to be covered in the analysis:

- Socio-demographics (specifically place of resident, income, education, age, number of children)

- Preferences regarding other modes of transport, usage and evaluation of (e-) carsharing

- Attitudes relevant to mobility issues (especially environmental awareness, affinity towards technology and innovation)

Therefore, the following sections provide a solid background of the differences between women and men referring to the recurrently identified characteristics of early adopters of carsharing and BEVs.

\section{Differences between women and men}

Numerous studies have proved that differences in mobility and transport behaviour between men and women are evident for metropolitan areas [6], aggregated for Germany [7], the USA [8, 29] or Dutch Monocentric and Policentric Urban Systems [30]. Mostly these differences result due to different social roles - to different gender. Even in developed western civilisations significant differences can be found comparing characteristics and social roles of women and men. The following part gives an overview of differences according to gender and sex of related topics (socio-demographic backgrounds, traffic behaviour and mobility related attitudes). Besides a general overview, a closer look at the Berlin Population as a reference group for the used sample is presented where possible.

\subsection{Socio-demographic differences between women and men}

Although women in western societies prevalently participate in the labour market as statistics show, additionally, they are more likely to take over household responsibilities and take care of children and relatives in need of care $[31,32]$. Therefore, parenthood has a crucial impact on gender: although the share of women without children working is almost as high as for men, it significantly changes as soon as a child, especially between 0 and 14 years, lives in the household [33]. Whereas childrened women are more likely to have a part time position when participating in labour market, men are more likely to increase their workload when a child is present in the household. Generally, women show lower incomes. One of the reasons is working part time; another is that women more often working in lower paid fields and positions. Even when considering work time, respective positon and qualifications, women earned $15 \%$ less than men in 2011 in Berlin [33].

When it comes to education, in recent years the share of female students in Germany increased to $49.5 \%$ [33]. With further academic education women are less represented to the point of $8.6 \%$ being female professors in Germany in 2003/04 [34]. Nevertheless, for the age category of under 30 years old Germans more women than men earned a university degree including universities of applied sciences [34]. For the group of people above this age men still have a greater share.

\subsection{Differences in mobility behaviour and preferences}

Due to the additional responsibilities of taking care, more women than men accompany children [35]. This leads to different traffic patterns. As mentioned before, a traffic gap has been identified between men and women: whereas men are more likely to travel further and have less destinations to cover, women on an aggregation have more complex trip chains with lower distances $[7,8,36]$. Especially in developed urban areas, patterns of women's traffic behaviour are similar across international studies [6-8]. Women take care of children by accompanying them when they have to go somewhere. In addition, when living in a multiperson household, women show a higher number of trips to run errands than the average [7]. Related places are usually not far from home, therefore, women show a complex radial net of trip chains over the day, whereas for most of the male travellers the way to work and back is an uninterrupted trip without (many) intermediate stops [37].

In addition, there are differences between female and male travellers already showing in early years in schools. Studies revealed that already for the time being in school boys tend to rather use individual traffic modes such as biking and driving [38]. Female adults from Berlin use bikes and cars less and public transportation more often than male adults [39]. Berlin, with a well-established public transportation infrastructure, takes on a leading position within Germany for the use of local public transportation: more than a third uses busses and local trains (almost) on a daily basis and only $13 \%$ responded 
(almost) never using those [39]. For the aggregated German population biking and using local public transportation systems show hardly any differences according to sex, solely women above 65 use local public transport system clearly more often than men in Germany [17]. When being grown up, women drive cars themselves less often than men [7]: for $43 \%$ of their trips women use the car compared to $58 \%$ of the trips of men, which is mainly due to a lower accessibility [40]. With an average of $11.5 \mathrm{~km}$ per trip, e-carsharing services could provide a sustainable tool for urban mobility. In 2008 the share of driver's licenses in Germany falls in line for both sexes with $29.2 \%$ women and $30.3 \%$ men. The almost balanced ratio is due to women between 40 and 60 having a higher share of driver's licenses and women between 18 and 39 and above 60 showing a smaller share than men [40]. A huge gap is revealed when looking at the kilometres travelled: German men cover with 1.103 .7 million km travelled by car a day almost twice of the distance of the total kilometres travelled compared to German women with only 512.6 million $\mathrm{km}$ travelled by car per day. The mean distance covered has been equal for women and men below the age of 29 and almost equal above 65 in 2008. In between, women cover only $10 \mathrm{~km}$ each way on average and men 16 to $17 \mathrm{~km}$ [40]. Parenthood and household responsibilities lead to women covering shorter distances since trips with a professional purpose including the way to work are more than twice as long as journeys to escort others [40].

\subsection{Differences in attitudes related to mobility issues}

Studies covering attitudes according to sex showed differences for the adaption of technology and environmental issues. Latter are not consistent though: In General, German and European women are slightly more aware of environmental concerns then men [9, 41, 42]. Environmental awareness expresses mostly on a local scale since women are more often concerned about household related aspects, such as waste separation and healthy food $[9,41]$. Regarding rather global issues, such as climate change, results vary for study to study. Contradicting findings have been presented for the USA and Europe: whereas women from the USA show slightly higher concerns about climate change than men, in Europe it was found to be vice versa [10, 43]. Stern, Dietz [44] found no difference in the strengths of value orientation and therefore respective actions, but women show stronger believes about the consequences of environmental issues expressed in information about particular consequences of environmental problems. They argue that there is no innate, biological difference in value orientation but rather due to shared experiences. These experiences differ between men and women and have different cultural influences. Differences in the attitude towards and use of technology are consistently showing a higher technological affinity for men than women due to stereotypical and most important homemade experiences $[45,46]$.

All these studies covering topics according to the identified characteristics of early adopters show the importance of sex expressing gender differences. Therefore, gender is central theme for mobility behaviour research. To address these findings, female early adopters will be analysed in contrast to male early adopters and in contrast to the respective Berlin population and the German average. Due to significant differences for most of the important characteristics of early adopters (see Section 2), female early adopters are expected to show significant differences for these characteristics as well.

\section{Research design}

In order to identify female early adopters and gain insights of their socio-demographic backgrounds, the behavioural impact of their attitudes and their evaluation of different aspects of carsharing, customers of two main carsharing operators ('Flinkster' and 'Multicity') in Berlin were asked about their mode choices, experiences and preferences. 'Flinkster' offers round-trip carsharing services with vehicles with ICEVs and BEVs; 'Multicity' offers the more flexible free-floating service with exclusively BEVs. The sample contains of 418 men and 74 women, 492 in total. At the point of conduction, customers can be considered as early adopters considering the market diffusion of carsharing with and without BEVs. In addition, it shows the same characteristics of early adopters, which have been identified in previous literature.

Respondents were asked to fill out an online survey between July and September 2013. Besides socio-demographic backgrounds, participants were asked about their behaviour and preferences of their mode choice as well as of integrated mobility services. Additionally, reasons for their choice of using carsharing services, experiences with several aspects of BEVs in carsharing, and their intention of using BEVs in the near future were included in the questionnaire. 27 questions were asked to generate mobility related attitudes and reconstruct the attitude-based typology [28]. Respondents were asked to state their agreement on a 6-point Likert scale $(0=$ I completely disagree, $5=$ I completely agree $)$ to specific items such as 'Environmental protection is crucial for me in my choice of transportation.' The questionnaire contained questions about the occupational status and number of children in the household as well. Nevertheless, it was only possible to find out about the respondents' gender by concluding from socio-demographic characterisations. Therefore, this analysis focusses on the respondents' sex since the gap between female and male users is strongly visible. Where applicable, differences for female and male respondents with and without children are presented. 
Since this paper aims for the effect of gender on ecarsharing, the influence of this one variable is analysed on all other variables and tested for significance. Therefore, all results that are presented in this paper show significant differences between female and male early adopters of carsharing with and without BEVs unless stated otherwise in the text. In a first step, the differences in socio-demographic backgrounds and characteristics of female early adopters to the Berlin population are being presented. Second, mode choice is being compared in addition to the frequency of usage per month and the usage within the past 12 month of different carsharing operators. These findings are set in relation to the characteristics of female Berliners and to the male early adopters and male Berliners. Differences between early adopters of different types of carsharing schemes can be seen in the presented studies. Carsharing might be operated with BEVs, ICEVs or offered as free-floating or as round-trip services. The questionnaire contained questions about various different operators. Table 1 lists the different carsharing operators and determines their aspects.

In order to see differences in usage of different types of carsharing, the stated usage was recoded into variables according to the different service types. This way, differences between the usage of BEVs and ICEVs in carsharing schemes and free-floating and round-trip services for women and men can be analysed.

Furthermore, mobility related attitudinal variables were analysed to identify differences between women and men. In addition, the distribution of the clusters of mobility related attitudes according to Hinkeldein et al. [28] is presented. The inconsistencies in previous studies about the attitudes regarding sex differences indicate either that there is not a specific sex more environmentally concerned than the other or that there are significant cultural differences that need to be taken into account. Additionally, different findings from data

Table 1 (E-) carsharing operators regarding types of services (included in questionnaire)

\begin{tabular}{|c|c|c|c|c|}
\hline Operator & Using BEVs & $\begin{array}{l}\text { Using } \\
\text { ICEVs }\end{array}$ & $\begin{array}{l}\text { Free-floating } \\
\text { service }\end{array}$ & $\begin{array}{l}\text { Round-trip } \\
\text { service }\end{array}$ \\
\hline Cambio & & $\mathrm{x}$ & & $\mathrm{x}$ \\
\hline Car2go & & $\mathrm{x}$ & $\mathrm{x}$ & \\
\hline Citeecar & & $\mathrm{x}$ & & $\mathrm{x}$ \\
\hline DriveNow & & $\mathrm{x}$ & $\mathrm{x}$ & \\
\hline Flinkster & & $\mathrm{x}$ & & $\mathrm{x}$ \\
\hline E-Flinkster & $\mathrm{x}$ & & & $\mathrm{x}$ \\
\hline Greenwheels & & $\mathrm{x}$ & & $\mathrm{x}$ \\
\hline $\begin{array}{l}\text { Hertz on } \\
\text { demand }\end{array}$ & & $\mathrm{x}$ & & $\mathrm{x}$ \\
\hline Multicity & $\mathrm{x}$ & & $\mathrm{x}$ & \\
\hline Stadtmobil & & $\mathrm{x}$ & & $\mathrm{x}$ \\
\hline
\end{tabular}

about early adopters about their attitudes suggest that there is not just one typical (e-) carsharing user. In order to compare the distribution of the clusters, first a confirmatory factor analysis recreated the reduction of the dimensionality of the data set to nine mobility related attitudes including reliability testing. The attitudinal indices were generated by computing the means of the variables loading on the respective factor. The following Table 2 gives an overview of the indices used in this analysis. Second, the respondents were allocated to the generated clusters according to mobility related attitudes [28].

\section{Results}

In order to identify female early adopters of carsharing and ecarsharing, a German sample of 492 carsharing subscribers from Berlin is analysed of which 74 are female early adopters. This sample generally confirms socio-demographic findings about early adopters as described before. The presentation of the results is structured according to the identified characteristics in Section 2. Although there is a relatively small share covering $15 \%$ of the sample - as usual for sample of early adopters of carsharing and BEVs, insights about female early adopters of carsharing with and without BEVs can be provided. First, the results of analysing socio-demographic backgrounds are being presented. Second, preferences in mode choice including a section about the use and evaluation of the e-carsharing service are described. Finally, mobility related attitudes and the clusters according to them are analysed.

\subsection{Socio-demographic characteristics of female early adopters}

As a first step to understand female early adopters, their characteristics are compared to those of males and the reference group of the Berlin population and Germany as shown in the following Table 3. In General, besides being male, the majority of the sample is well-educated and full-time employed with a high income. Differentiating between women and men, the socio-demographic backgrounds remain homogenous except for the average age, the employment status and the net household income per month. $50 \%$ of the women are between 27 and 35 and accordingly 3.3 years younger on the aggregated level than men.

Although the sample shows a higher share of full-time employment than found in Berlin, which is nearly equal for men and women if no child lives in the household, the typical gap occurs as soon as a child lives in the household, nearly aligning with the share of the Berlin population. Childrened female early adopters show, therefore, the same effects of parenthood on the employment status as elsewhere in Berlin, Germany or Europe. The levels of education are equal on the aggregated level and are much higher than the German and Berlin average. 
Table 2 Mobility related attitudes, indices generated from $-(n=492$, Berlin $)$

Factor Item example (item loading most highly on the factor)

No. of items Cronbach's $\alpha$ loading on the factor
Car affinity

Bike affinity

PT affinity

Long-distance train affinity

Mobility service affinity

Owning a car affinity

Mobility related environment affinity

Technology affinity

Innovator scale

\author{
I find driving an easy way for getting around. \\ I find cycling an easy way for getting around. \\ I reach my destination without stress when using public transport. \\ I find using the train an easy way for getting around. \\ The use of mobility services allows me to reach all my important destinations. \\ I am dependent on my car in my daily life. \\ Environmental protection is crucial for me in my choice of transportation. \\ I am quickly able to figure out unknown electronic devices. \\ Other people often discover new travel ideas thanks to me.
}
0.808
0.923
0.825
0.872
0.869
0.857
0.881
0.825
0.870

Interesting is the income gap, which is bigger than usual: a third of the women have a net household income below 2000 Euro a month; whereas, only every fifth men receive less than 2000 Euro a month. This gap is bigger than the regular gap found for the Berlin population. This can be explained with carsharing offering a cheaper access to using a car when needed instead of having to own a car. More than three quarter of the women $(77 \%)$ in the sample do not have a car in the household compared to less than a third of the men (64\%).

The number of children is different but not on a significant level: the male share of the sample has 0.68 children on average, while the female share has 0.48 . Splitting the data according to two age categories of the children, it shows that the difference lies within the group for children younger than 14 years: more than half of the women stated not having children below 14 compared to a third of the men (Fig. 1). Concluding from the employment status (men with children are usually more often full-time employed than without children and women are usually a lot more often part-time employed with children than without), women reduce their work time in order to take care of their child or children. This effect leads to the assumption that using carsharing with and without BEVs schemes is not as attractive to people taking care of children - and this means usually women.

To sum it up, regarding socio-demographic backgrounds there are significant differences regarding age, employment

Table 3 Comparison of socio-demographic characteristics $-(n=492$, Berlin $)$

\begin{tabular}{|c|c|c|c|c|c|c|}
\hline & & $\begin{array}{l}\text { Female Early } \\
\text { Adopters } \\
\text { Berlin }\end{array}$ & $\begin{array}{l}\text { Male } \\
\text { Early Adopters } \\
\text { Berlin }\end{array}$ & $\begin{array}{l}\text { Berlin } N=492, \\
\text { July/August } 2013\end{array}$ & $\begin{array}{l}\text { Average } \\
\text { Berlin } \\
\text { (women/men) }\end{array}$ & $\begin{array}{l}\text { Average } \\
\text { Germany }\end{array}$ \\
\hline Sex & Female & $100 \%$ & - & $15.4 \%$ & $51.0 \%{ }^{\mathrm{a}}$ & $51.0 \%^{\mathrm{b}}$ \\
\hline \multirow[t]{5}{*}{ Age } & $17-24$ & $8.9 \%$ & $4.3 \%$ & $4.3 \%$ & $8.7 \%{ }^{\mathrm{a}}$ & $9.8 \%{ }^{\mathrm{b}}$ \\
\hline & $25-39$ & $58.9 \%$ & $51.9 \%$ & $50.8 \%$ & $22.4 \%{ }^{\mathrm{a}}$ & $21.3 \%{ }^{\mathrm{b}}$ \\
\hline & $40-49$ & $17.9 \%$ & $25.5 \%$ & $26.9 \%$ & $16.2 \%{ }^{\mathrm{a}}$ & $19.9 \%^{\mathrm{b}}$ \\
\hline & $50-64$ & $14.3 \%$ & $14.7 \%$ & $14.6 \%$ & $19.2 \%{ }^{\mathrm{a}}$ & $24.3 \%{ }^{\mathrm{b}}$ \\
\hline & $65+$ & - & $3.5 \%$ & $3.4 \%$ & $19.9 \%{ }^{\mathrm{a}}$ & $24.6 \%{ }^{\mathrm{b}}$ \\
\hline $\begin{array}{l}\text { Graduated from university } \\
\text { or technical college }\end{array}$ & & $66.7 \%$ & $66.7 \%$ & $66.7 \%$ & $\begin{array}{l}19.5 \%^{\mathrm{a}} \\
(17.8 \% / 21.3 \%)\end{array}$ & $15.1 \%{ }^{\mathrm{b}}$ \\
\hline \multirow[t]{3}{*}{ Full-time employed } & Total & $62.3 \%$ & $79.2 \%$ & $76.6 \%$ & $\begin{array}{l}64.8 \%{ }^{\mathrm{a}} \\
(57.6 \% / 71.1 \%)\end{array}$ & $62.3 \%^{\mathrm{c}}$ \\
\hline & Without children & $76.9 \%$ & $78.3 \%$ & $78.0 \%$ & $\begin{array}{l}66.7 \%^{\mathrm{a}} \\
(62.6 \% / 70.1 \%)\end{array}$ & - \\
\hline & With children & $53.8 \%$ & $84.2 \%$ & $80.7 \%$ & $\begin{array}{l}61.4 \%{ }^{\mathrm{a}} \\
(49.8 \% / 73.0 \%)\end{array}$ & - \\
\hline $\begin{array}{l}\text { Net household income } \\
\text { per month }\end{array}$ & $<2000 €$ & $36.2 \%$ & $20.3 \%$ & $22.6 \%$ & $\begin{array}{l}48.1 \%^{\mathrm{a}} \\
(49.7 \% / 46.4 \%)\end{array}$ & $50.1 \%{ }^{\mathrm{a}}$ \\
\hline
\end{tabular}

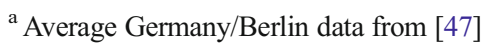

${ }^{\mathrm{b}}$ Average Germany data from [48]

${ }^{\mathrm{c}}$ Average Germany data from [17] 


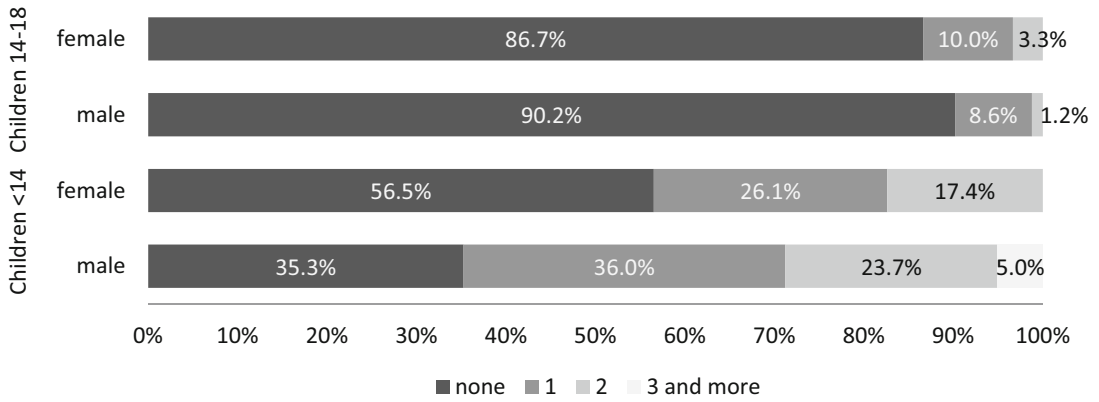

Fig. 1 Respondents with and without children $-(n=492$, Berlin $)$

status and income between female and male early adopters of carsharing with and without BEVs: female early adopters are younger, less often full-time employed when children live in the household and show a lower income than male early adopters, although latter is still higher than the average of female Berliners. Women of this sample are more often fulltime employed than on an average, especially when they do not have children in the household. As expected, having a child shows a big effect on the status of employment: female early adopters with children work less often full-time. The number of children is smaller for women than for men, whereas no comparable data for Germany or Berlin is available. This aspect and the effect of having children in the household on the employment status suggest that carsharing is rather attractive to people not being in charge of taking care of their children.

\subsection{Differences in mode choice and use of carsharing with and without BEVs}

This part provides insights about different aspects regarding mode choice and the use and evaluation of e-carsharing services. Female early adopters show different preferences in mode choice compared to men: they are using bikes with $80 \%$ at least once a week compared to men with $62 \%$. Cars including BEVs and rented cars are not used as often by women as by men. Women do not show a higher usage of public transportation as it has been identified in other international studies before and described in Section 3.2. Regarding the use of free floating carsharing with BEVs, $10 \%$ of the women use this service for professional reasons compared to $24 \%$ of the men. When cleaning according to employment status, the difference remains. This could be explained with different work tasks for women and men, which were not asked for in the survey. Additionally, more than half of the women almost never or less than once a month use a car driving themselves (53\%) compared to a third of the men (37\%).

Comparing the use of different carsharing service operators, differences between women and men occur mostly checking for the average frequency of use per month generated out of the past 12 months. As Table 4 shows, for most of the service operators, men have used carsharing services more often. Only regarding the use of 'Multicity' the average number of uses is almost equal for both groups of early adopters. For one of the main service operators 'Flinkster', there is a much higher share of men using this service: almost half of the men used 'Flinkster' at least once within the past 12 months compared to a quarter of the women. 'Flinkster' is a station based carsharing service operator with vehicles with an internal combustion engine. Other operators namely 'Citeecar', 'Greenwheels', 'Hertz on demand', 'Cambio', 'Stadtmobil' and others do not play a role for the female users of this sample. $14.5 \%$ of the male respondents used others though. On average, respondents had 2.2 memberships. Women show a significantly smaller number of memberships with $1.8 \mathrm{com}-$ pared to men with 2.4.

Additionally, women show shorter membership periods for all operators than men. Nevertheless, a slightly higher share of the women who used 'Multicity' within the past 12 months can be found. 'Multicity' offers only one model of BEV (Citroen C-Zero). The higher share of female early adopters using the service of 'Multicity' can be explained by the fact that women prefer using one type of car when using carsharing: $73 \%$ of the women agreed, whereas $52 \%$ of the

Table 4 Use of different (e-) carsharing operators of members of 'Flinkster' and 'Multicity'- $(n=492$, Berlin $)$

\begin{tabular}{|c|c|c|c|c|}
\hline $\begin{array}{l}\text { Carsharing } \\
\text { service } \\
\text { operator }\end{array}$ & $\begin{array}{l}\text { Mean } \\
\text { frequency } \\
\text { used per } \\
\text { month } \\
\text { Female }\end{array}$ & $\begin{array}{l}\text { Mean } \\
\text { frequency } \\
\text { used per } \\
\text { month } \\
\text { Male }\end{array}$ & $\begin{array}{l}\text { Used } \\
\text { within past } \\
12 \text { month } \\
\text { Female }\end{array}$ & $\begin{array}{l}\text { Used } \\
\text { within past } \\
12 \text { month } \\
\text { Male }\end{array}$ \\
\hline Total & 4.5 & 5.8 & $95.2 \%$ & $91.3 \%$ \\
\hline Multicity & 2.2 & 2.1 & $65.2 \%$ & $65.0 \%$ \\
\hline DriveNow & 2.5 & 2.8 & $40.6 \%$ & $50.6 \%$ \\
\hline Car2go & 1.9 & 2.1 & $33.3 \%$ & $50.4 \%$ \\
\hline Flinkster & 0.4 & 0.9 & $24.6 \%$ & $46.3 \%$ \\
\hline E-Flinkster & 0.4 & 0.4 & $23.2 \%$ & $29.1 \%$ \\
\hline $\begin{array}{l}\text { Other } \\
\text { Operators }\end{array}$ & 0.0 & 0.7 & $2.9 \%$ & $14.5 \%$ \\
\hline
\end{tabular}


men prefer always using the same type of car. Therefore, it can be argued that female early adopters do not use carsharing services because of trying different models as much as men do, but rather because of having to run errands that are difficult to realize by other modes of transport, especially by bike. Always using the same car model provides a higher potential of routinizing the use of carsharing. After 'Multicity', 'DriveNow' shows the highest rates of usage although a gap for both the frequency of use and share of users can be identified comparing women and men. At this point, the reader needs to bear in mind that the sample consists of members of 'Flinkster' and 'Multicity' and, therefore, the order of the operators is not representing early adopters in general. Nevertheless, the ratio of women and men using the services reveals that women show a higher affinity towards BEVs. Since 'Multicity' is the only operator using only one model of BEV, it achieves the highest share of female users and frequency of use per month. Women in the sample agreed significantly less with statements like 'a car in the household is part of their life' and that 'their car is needed for staying in contact with friends' compared to men. This leads to the conclusion that owning a car is even less important to female early adopters than for males. Another difference can be found in the evaluation of handling of charging the battery and handling the charging station: more than half of the women experienced the battery charging as very positive compared to a third of the men. Using the charging station, $40 \%$ of the women stated a very positive handling experience, whereas not even $20 \%$ of the men stated the same.

Splitting the different operators according to their specific characteristics as determined in Table 1, almost $80 \%$ of the females have used BEVs compared to $65 \%$ having used ICEVs within the past 12 month (Fig. 2). For the male respondents the share having used ICEVs is slightly bigger than the one for BEVs. The difference of the use of ICEVs is highly significant. This clearly states that women using carsharing show a higher tendency to use BEVs instead of ICEVs. Comparing free-floating to round-trip (e-) carsharing schemes, latter shows another significant gap between women and men: whereas a bit more than a third of the females used round-trip services, almost $60 \%$ used them.

Since the usage rates are generally smaller for women, the fact that operators with BEVs (free-floating and round-trip services) show a higher share of women using the services than the services with ICEVs, it can be argued that female carsharing subscribers show a higher potential for the use of BEVs instead of ICEVs. Significantly more women than men (76/63\% agreed) reporting that they have found a vehicle whenever they needed one and describing the business area as big enough for their daily trips (64/50\%), supports the argument of women's traffic patterns being optimal for urban e-carsharing schemes. Men and women report almost equally about the intention of using e-carsharing services in the near future: $88 \%$ of the men intend to use electric vehicles through sharing schemes on a regular basis compared to $85 \%$ of the women.

Having children in the household does not lead to significant differences between women and men regarding the presented variables of usage. This suggests that using these services takes place mainly without children. Therefore, no effect of the variables can be seen.

\subsection{Differences in mobility related attitudes}

At this point attitudinal variables are used to compare men and women in order to get insights about female early adopters. Nine indices were computed using 27 attitudinal variables as described in Section 4. The sample shows a high affinity for new mobility services and bike affinity. Although there is a high car affinity across the sample, male and female early adopters show a very low preference for owning a car.

Comparing the indices regarding attitudinal parameters, three main differences can be identified between women and men: as seen before, female early adopters use bikes more often compared to men. This characteristic is confirmed by a higher affinity towards riding bikes. Additionally, differences regarding affinity towards technologies and the attitude
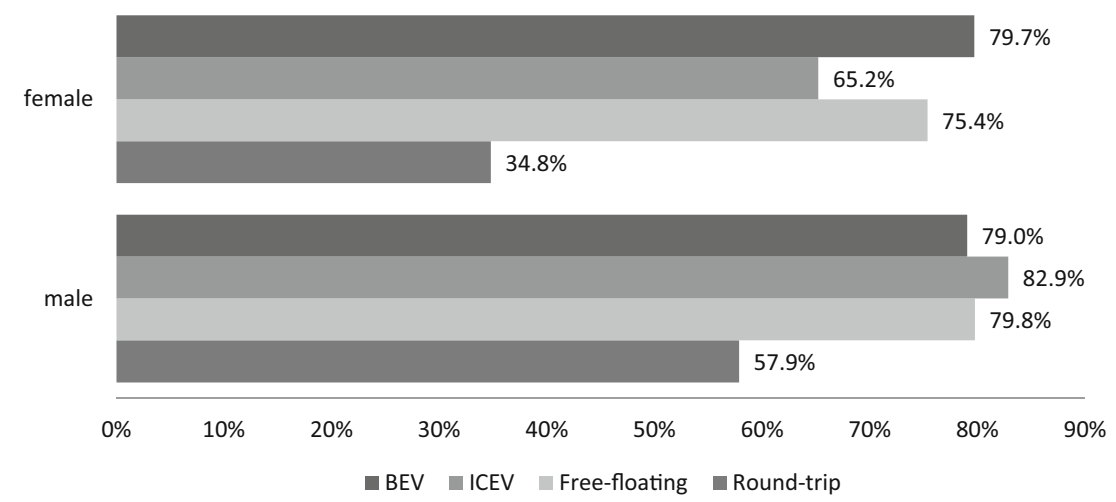

Fig. 2 Differences in (e-) carsharing usage between women and men - $(n=492$, Berlin $)$ 
Table 5 Mobility related attitudes $-(n=492$, Berlin $)$

\begin{tabular}{lll}
\hline Factor & $\begin{array}{l}\text { Female early } \\
\text { adopters }\end{array}$ & $\begin{array}{l}\text { Male early } \\
\text { adopters }\end{array}$ \\
\hline Car affinity & 3.2 & 3.2 \\
Bike affinity** & 4.0 & 3.6 \\
PT affinity & 3.5 & 3.5 \\
Long-distance train affinity & 3.1 & 3.2 \\
Mobility service affinity & 3.9 & 3.9 \\
Owning a car affinity & 0.9 & 1.3 \\
Mobility related environment affinity & 3.3 & 3.2 \\
Technology affinity** & 2.7 & 3.7 \\
Innovator scale* & 2.9 & 3.2 \\
\hline
\end{tabular}

$* * p<0.005 ; * p<0.05$

towards innovations can be seen. Table 5 shows the means of the indices comparing women and men.

Grouping the sample according to the clusters used according to Hinkeldein et al. [28], the overall sample is dominated by 'innovative technology-loving multioptionals' and 'ecological PT-and -bike lovers' as shown in Fig. 3. The two groups can be characterised with a high mobility related environment awareness, mobility service affinity, PT affinity, long-distance train affinity and innovator scale. Differences can be found regarding the joy of car driving and general car affinity and the affinity towards new technologies. This supports the assumption that female carsharing subscribers use the services not to test different car models, but rather as an additional multimodal part of urban mobility.

Although there is neither an identified significant difference in the attitude regarding affinity towards local public transportation, nor a difference in the usage of it between men and women, the distribution of mobility types across the sample shows a greater share of female 'ecological PT- and -bike lovers' compared to male early adopters. More than half of the male sample can be allocated to the group of 'innovative technology-loving multioptionals' and a third to 'ecological PT-and-bike lovers'. The shares of the two groups for women are nearly equal with $44 \%$ each. This allocation is consistent with the findings of Hinkeldein et al. [28], where two thirds of the cluster 'innovative technology-loving multioptionals' and a bit than half of the cluster 'ecological PT-and -bike lovers' are male. The cluster of 'flexible carlovers' shows a high affinity towards driving and testing cars. Nevertheless, they do not generally reject other modes of transport. Although for both sexes the share of 'flexible carlovers' is about 9 to $10 \%$, the previously identified differences have to lie within the two remaining clusters ('innovative technology-loving multioptionals' and 'urban oriented PTlovers').

The differences in the attitudes and distribution of the clusters according to mobility related attitudes indicate that early adopters show a high ecological awareness and have a high affinity towards public and individual traffic. Nevertheless, clusters that clearly prefer PT and show a high environmental awareness ('urban oriented PT-lovers') as well as clusters that show a higher affinity towards cars ('traditional car-lovers') or bikes ('conventional bike-lovers') are hardly represented in the sample of early adopter. For the biggest clusters of the sample driving oneself either by car or by bike in combination with public transport is an important criterion. For the women of the sample the individual traffic is mostly by bicycle; for the men it stands for car usage. Clearly, the more sustainable way of transport is by bicycle. Therefore, female early adopters show higher environmental friendly traffic behaviour than male, although the attitude towards ecological issues does not show differences between these two groups. If women used carsharing, they rather used locally environmental friendly battery electric vehicles in carsharing than men.
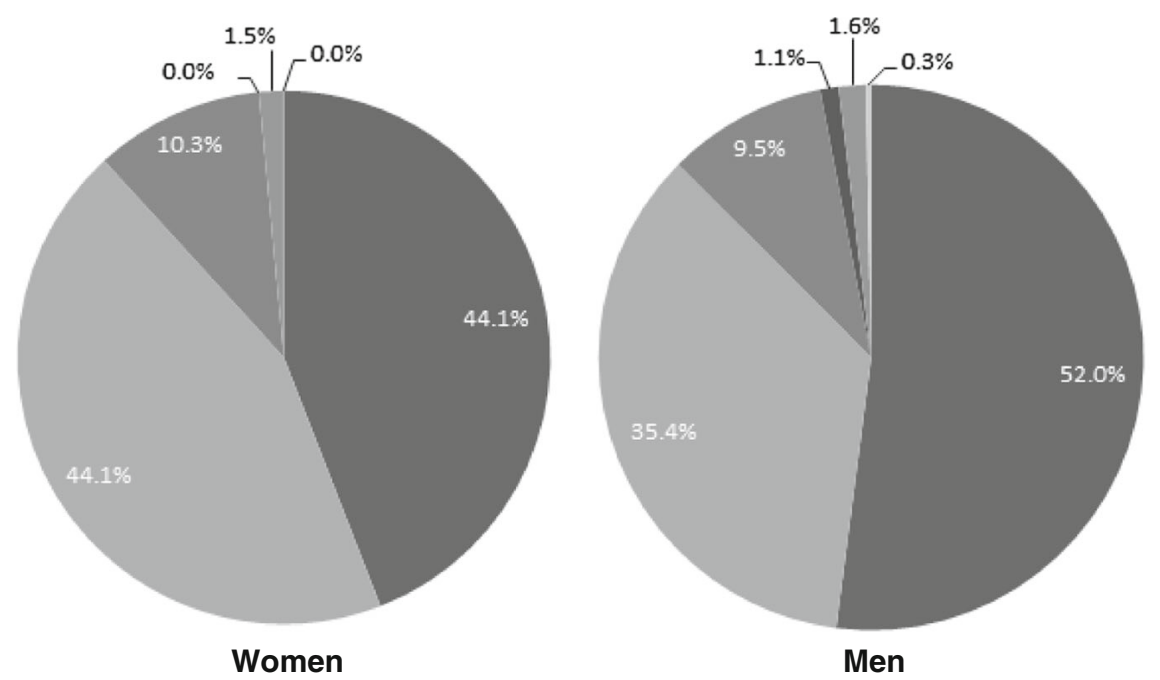

Innovative technologyloving multioptionals

Ecological PT- and bikelovers

Flexible car-lovers

- Traditional car-lovers

Urban oriented PT-lovers

Conventional bike-lovers

Fig. 3 Distribution of clusters according to mobility related attitudes $-(n=492$, Berlin $)$ 
Although the sample does not show great differences in the attitude towards mobility related environmental issues, $60 \%$ of the women agreed completely on the statement of BEVs being environmentally friendly, compared to men with $43 \%$. This indicates that's women are not as sceptical about the environmentally effects of BEVs.

\section{Conclusion}

In order to generate a shift towards sustainable mobility, the needs of potential customers have to be identified. The focus on male early adopters has to be overcome and other groups of potential customers need to be addressed. For the first time a sample of early adopters was analysed with a special focus on female early adopters. Besides socio-demographic characteristics, mode choice including the evaluation of e-carsharing and mobility related attitudes were included in the analysis. Although the sample does not contain a high share of women, it was possible to gain insights out of the subsample size of 74 female early adopters.

Comparing female and male carsharers revealed significant differences in socio-demographics, especially in age, income and full-time employment status when children live in the household. The accessibility to driving a car when needed, which carsharing services offer, helps overcoming the income gap. The business areas of carsharing operators fit women's urban traffic patterns since they usually cover shorter distances compared to men. As shown, female early adopters show a high potential for using BEVs in carsharing services. If women use free-floating carsharing services, they are more likely to choose operators offering BEVs. This hypothesis is supported by the fact that women prefer one type of car instead of trying different models. Female early adopters use bikes more often and ICEVs and BEVs less often compared to men. The analyses of mode choice, the use and evaluation of e-carsharing as well as the attitudinal variables suggests that female early adopters tend to use carsharing services in the original meaning as an additional part for urban mobility and not for testing car models as much as men do. In addition, it was possible to show that it is important to address different types of carsharing services to respective potential customers.

In general, children significantly change the traffic patterns of women. At this point the influence of children remains unclear since no differences can be found between men and women with and without children in this sample. It is suspected that the services do not offer an adequate solution to accompany children. In order to address more women as potential customers, this effect needs to be addressed in further research. Qualitative interviews will provide a deeper understanding of the obstacles of using round-trip and free-floating carsharing services that other potential customer groups than the known early adopters might face when covering complex trip chains.
All these findings are preliminary. Nevertheless, they show that carsharing operators need to discover the potential of women as customers to provide a more sustainable urban mobility culture. These findings need to be confirmed by analysing more samples according to sex or gender. It is necessary to analyse not merely a single group of potential customers or simply one market segment. It is of crucial importance for understanding transportation, since gender continues to play an important role explaining traffic behaviour [3]. In addition, the differentiation of carsharing with and without BEVs schemes showed that the services cover different aspects that need further attention. Comparing the findings of this study to a representative sample will shed light on the difference of the behavioural impact of mobility related attitudes and can help understanding the requirements of women in order to support the use of carsharing.

Acknowledgments The analysis presented in this paper is kindly supported by InnoZ - Innovation Centre for Mobility and Societal Change, Germany by providing the data of the research project 'BeMobility 2.0' funded by German Federal Ministry of Transport, Building and Urban Development (BMVBS).

Open Access This article is distributed under the terms of the Creative Commons Attribution 4.0 International License (http:// creativecommons.org/licenses/by/4.0/), which permits unrestricted use, distribution, and reproduction in any medium, provided you give appropriate credit to the original author(s) and the source, provide a link to the Creative Commons license, and indicate if changes were made.

\section{References}

1. Globisch J et al. (2013) Early adopter unter der Lupe. Elektroautos wer ist jetzt schon e-mobil und wer kann sich vorstellen, eines zu kaufen? Int Verkehrswesen 65(2):46-49

2. Hjorthol R (2013) Attitudes, ownership and use of electric vehicles-a review of literature. National Academy of Sciences

3. Burkhardt JE, Millard-Ball A (2006) Who is attracted to carsharing? Transp Res Rec: J Transp Res Board 1986:98-105

4. Lane C (2005) PhillyCarShare: first-year social and mobility impacts of carsharing in Philadelphia, Pennsylvania. Transp Res Rec: J Transp Res Board 1927:158-166

5. Stillwater T, Mokhtarian P, Shaheen S (2009) Carsharing and the built environment. Transp Res Rec: J Transp Res Board 2110:27-34

6. Gordon P, Kumar A, Richardson HW (1989) Gender differences in metropolitan travel behaviour. Reg Stud 23(6):499-510

7. Nobis C, B. Lenz (2005) Gender differences in travel patterns. Research on Women's Issues in Transportation, p. 114.

8. Rosenbloom S (2000) Trends in women's travel patterns. in Women's Travel Issues Second National Conference

9. Umweltbewusstsein in Deutschland, Ergebnisse einer repräsentativen Bevölerungsumfrage. 2012, Umweltbundesamt: Berlin, Marburg.

10. Special Eurobarometer 313: Europeans' attitudes towards climate change. 2009, European Commission, European Parliament

11. Halden D (2003) Children's attitudes to sustainable transport

12. Trommer S, J Jarass, V Kolarova (2015) Early adopters of EVs in Germany unveiled - Results of a study among private users of EVs in Germany. in 28th International Electric Vehicle Symposium and 
Exhibition. Deutsches Zentrum für Luft- und Raumfahrt (DLR), Kintex

13. Peters A, J Hoffmann (2011) Nutzerakzeptanz von Elektromobilität. Eine empirische Studie zu attraktiven Nutzungsvarianten, Fahrzeugkonzepten und Geschäftsmodellen aus Sicht potenzieller Nutzer. Karlsruhe p 34.

14. Saarenpää J, Kolehmainen M, Niska H (2013) Geodemographic analysis and estimation of early plug-in hybrid electric vehicle adoption. Appl Energy 107:456-464

15. Erdem C, Șentürk İ, Șimșek T (2010) Identifying the factors affecting the willingness to pay for fuel-efficient vehicles in Turkey: a case of hybrids. Energ Policy 38(6):3038-3043

16. Hanappi T et al. (2012) Elektromobilität in Österreich. Determinanten für die Kaufentscheidung von alternativ betriebenen Fahrzeugen: Ein diskretes Entscheidungsexperiment. Umweltbundesamt: Wien.

17. Mobilitaet in Deutschland 2008 - Ergebnisbericht. Struktur Aufkommen - Emissionen - Trends. 2010, Bundesministerium für Verkehr Bau und Stadtentwicklung, Institut für angewandte Sozialwissenschaft (infas), Deutsches Zentrum für Luft- und Raumfahrt (DLR) Bonn, Berlin.

18. Hackbarth A, Madlener R (2013) Consumer preferences for alternative fuel vehicles: a discrete choice analysis. Transp Res Part D: Transp Environ 25:5-17

19. Pierre M, Jemelin C, Louvet N (2011) Driving an electric vehicle. A sociological analysis on pioneer users. Energ Effic 4(4):511-522

20. Jensen AF, Cherchi E, Mabit SL (2013) On the stability of preferences and attitudes before and after experiencing an electric vehicle. Transp Res Part D: Transp Environ 25:24-32

21. Tran M et al. (2013) Simulating early adoption of alternative fuel vehicles for sustainability. Technol Forecast Soc Chang 80(5):865875

22. Firnkorn J (2012) Triangulation of two methods measuring the impacts of a free-floating carsharing system in Germany. Transp Res A Policy Pract 46(10):1654-1672

23. Firnkorn J, Müller M (2011) What will be the environmental effects of new free-floating car-sharing systems? The case of car2go in Ulm. Ecol Econ 70(8):1519-1528

24. Petersen M (1995) Ökonomische Analyse des Car-Sharing. Wiesbaden.

25. Costain C, Ardron C, Habib KN (2012) Synopsis of users' behaviour of a carsharing program: A case study in Toronto. Transp Res A Policy Pract 46(3):421-434

26. Efthymiou D, Antoniou C, Waddell P (2013) Factors affecting the adoption of vehicle sharing systems by young drivers. Transp Policy 29:64-73

27. Schuitema G et al. (2013) The role of instrumental, hedonic and symbolic attributes in the intention to adopt electric vehicles. Transp Res A Policy Pract 48:39-49

28. Hinkeldein D et al. Who Would Use Integrated Sustainable Mobility Services - And Why?, in Sustainable Urban Transport. p. 177-203.

29. Crane R (2007) Is there a quiet revolution in women's travel? Revisiting the gender gap in commuting. J Am Plan Assoc 73(3): 298-316
30. Schwanen T, Dieleman FM, Dijst M (2001) Travel behaviour in Dutch monocentric and policentric urban systems. J Transp Geogr 9(3):173-186

31. Dribe M, Stanfors M (2009) Does parenthood strengthen a traditional household division of labor? Evidence from Sweden, national council on family relations. J Marriage Fam 71(1):33-45

32. Schneebaum A, K Mader (2013) The gendered nature of intrahousehold decision making in and across Europe, in Department of Economics Working Paper Series, W.V.U.o.E.a. Business, Editor: Vienna

33. Gender Datenreport Berlin 2012, in Berlin Senate Department for Integration, Labour and Social Issues (BSDILS). 2012, Amt für Statistik Berlin-Brandenburg.

34. Datenreport zur Gleichstellung von Frauen und Männern in der Bundesrepublik Deutschland, in Gender-Datenreport. 2005, Deutsches Jugendinstitut, Statistisches Bundesamt: München.

35. Turner T, Niemeier D (1997) Travel to work and household responsibility: new evidence. Transportation 24(4):397-419

36. Bauhardt C (1999) Bürgersteige und Straßenbahnen für die Frauen den Männern ICE und Transrapid? In: Collmer S, Döge P, Fenner B (eds) Technik, Politik, Geschlecht. Kleine Verlag, Bielefeld

37. VCÖ, Gender Gap im Verkehrs- und Mobilitätsbereich, Hintergrundbericht. 2009, VCÖ - Verkehrsclub Österreich Wien.

38. Richter B (2009) Das Verkehrsverhalten von deutschen und schweizerischen Jugendlichen im Vergleich. mobilogisch. Zeitschrift für Ökologie, Politik \& Bewegung, 3/10: p. 40-43.

39. Mobilität in Städten -SrV 2008: Sample Berlin. Analysis by TU Dresden/VIP. 2008, Senate department for urban development and the environment Berlin, Department Traffic: Berlin.

40. Stiewe M, L. Krause (2012) Geschlechterverhältnisse und Mobilität-Welchen Beitrag leisten Mobilitätserhebungen? Schwechat

41. Mohai P (1992) Men, women, and the environment: an examination of the gender gap in environmental concern and activism. Soc Nat Resour 5(1):1-19

42. Schahn J, Holzer E (1990) Studies of individual environmental concern: the role of knowledge, gender, and background variables. Environ Behav 22(6):767-786

43. McCright AM (2010) The effects of gender on climate change knowledge and concern in the American public. Popul Environ 32(1):66-87

44. Stern PC, Dietz T, Kalof L (1993) Value orientations, gender, and environmental concern. Environ Behav 25(5):322-348

45. Harris TA, Gale MT, Colley AM (1994) Effects of gender role identity and experience on computer attitude components. J Educ Comput Res 10(2):129-137

46. Venkatesh V, Morris MG, Ackerman PL (2000) A longitudinal field investigation of gender differences in individual technology adoption decision-making processes. Organ Behav Hum Decis Process 83(1):33-60

47. Mikrozensus 2012. 2012, Amt für Statistik Berlin-Brandenburg: Berlin.

48. Zensus 2011. 2014, Statistische Ämter des Bundes und der Länder, Wiesbaden 